\title{
A review of a stand-alone Hydrogen system application for private houses in Greece and the use of Phase change materials in their building construction.
}

\author{
Leonidas C. Raptis ${ }^{*}$, Giouli K. Mihalakakou' ${ }^{1}$,Evangelos I. Gkanas ${ }^{2}$, Sofoklis S. Makridis ${ }^{1}$ \\ ${ }^{1}$ Department of Environmental and Natural Resources Management, University of Patras, Seferi Street, 30100 \\ Agrinio, Greece; raptilos@yahoo.com (L.R.); pmichala@upatras.gr (G.P.); smakridis@ upatras.gr (S.M.); \\ ${ }^{2}$ School of Mechanical, Aerospace and Automotive Engineering, Coventry University, CV1 5FB, Priory Street, \\ Coventry, UK; ac1029@ coventry.ac.uk
}

*Corresponding author: Leonidas C. Raptis, Civil Enginneer, B.Eng(Hons), MSc.

Tel.: (0030) 6979117008, Fax No: (0030) 2231104015, e-mail: raptilos@ yahoo.com, Address: 96 Makropoulou str., Lamia, 35131, Greece.

\begin{abstract}
Energy is a fundamental ingredient in economic development and energy consumption is an index of prosperity and the standard of living. The consumption of energy has increased significantly in the last number of decades, as the standard of living has improved. Renewable energy is a sustainable and clean source of energy derived from nature. Renewable energy technology is one of the solutions, which produces energy by transforming natural resources into useful energy forms. When you do something for the first time in the world, you never attain a perfect product or solution from the start. In Central Greece Lamia city, we are the first to design and implement an off-grid energy system using hydrogen energy storage technology and phase change materials for a house residence. The action plan for energy efficiency, a series of directives and incentive mechanisms, mandatory energy certification of buildings, indicate the urgent need to reduce energy consumption in buildings, which results in a more comfortable living, long service life of buildings, which in turn preserves the environment.
\end{abstract}

Keywords: Stand-alone hydrogen systems, Off-grid systems, Hydrogen, Electrolysis, Electrolyzer, Fuel Cell, Phase Change materials (PCM's), Bioclimatic design.

\section{List of Tables}

Table 1: Annual sunshine duration (in hours) in Lamia, Greece

\subsection{Introduction}

The building sector, which is consisting of the residential and tertiary sector, consumes the $37 \%$ of the final energy in Greece according to the national report of the Greek Centre for Renewable Energy Sources and Saving (CRES) for Energy Efficiency trends and policies in Greece. Since 2000 to 2016, the final energy consumption in households has decreased by $16 \%$. Although until 2006 the households' final consumption was steadily increased, the households sector was one of the first sectors which sustain the effects of the economic recession in final energy consumption. This fact, in combination with the energy efficiency new Laws that have been implemented since 2007, led to the decrease of final energy consumption of household sector.

The introduction of Natural Gas in 1998 and the final energy consumption of renewable energy sources has also increased by $26 \%$ over this period, mainly because of the implemented measures to promote the renewable energy sources in all sectors which resulted to the increasing of the participation of renewable sources and materials in the final energy consumption from 6\% in 2000 to $9 \%$ in 2013. Finally, mainly because of the increasing of heating oil cost in the last years, the share of electricity consumption in the final consumption has increased from $20 \%$ in 2000 to $27 \%$ in 2013, leading to the reduction of the share of oil products in the final energy mix of the country. However oil products remain the dominant energy source of final consumers in Greece. [1]

According to the Hellenic Statistical Authority (EL.STAT) [2], buildings constructed before 1980 represent the $74.6 \%$ of buildings in Greece and are classified in the first category that represents buildings with no thermal insulation protection. The second category consists of dwellings constructed during the period 1980-2001 which in the majority are partially insulated. The third category includes buildings that were constructed from 2001 up to now consist by well insulated materials. 
In Greece there was no specific regulation concerning the energy performance and certification of buildings until the Energy Performance of Buildings Directive (EPBD) [3]. As there were no energy performance requirements in Greece - other than the maximum $U$ values for new constructions build after 1981 - the implementation of the EPBD clearly has impact on the severity of the requirements in terms of energy efficiency, sometimes leading to energy conservations of up to $20-40 \%$. Since new buildings should meet the minimum energy requirements when being constructed, a clear reduction of the energy consumption for new buildings is expected and hopefully a change in tendency towards building more efficient buildings.

In general, the requirements introduced in the country through the Greek Energy Performance Regulation (KENAK) [4] do not differentiate much from those that already existed.

In October 2012, the European Commission adopted the new Directive 2012/27/EU [5] on energy efficiency with clear focus on achieving the overall energy efficiency target of reducing primary energy consumption by $20 \%$ by 2020 . The Directive $2012 / 27 /$ EC was transposed into Greek legislation by the Law 4342/2015. [6] The target for 2020 is derived from estimates of the development of both the Greek economy, and the implementation of measures, actions and programmes for improving energy efficiency, penetration of renewable energy sources and achieving energy savings in final consumption and primary energy production.

There were plenty of European programmes the past years for improving energy efficiency and achieving energy savings in final consumption and primary energy production in Greece. One of them is the Energy saving program [7]. The purpose of the "Energy saving" programme is the implementation of actions and proven best practices for reducing energy consumption in houses and public buildings. There were a lot of actions for the energy upgrade of building envelopes, upgrade of the lighting system, and energy upgrade of electro-mechanical installations, including all relevant operations or the use of renewable resources. The programme had followed the complete construction of new bioclimatic buildings under KENAK, photovoltaic facilities, central solar thermal hot water systems, new energy systems, construction of a high efficiency cogeneration of heat and power facility, construction of a facility for making use of the heat produced from Renewable Energy Sources facility for cooling purposes, other RES systems for heat and cooling energy and heat pumps, etc.

Every day factors, like the energy prices and the rise in temperature, especially in the urban areas, are forcing people to think about cost-effective energy solutions, like the use of passive cooling techniques (night ventilation, solar shading etc.), or even more advanced techniques like cool paints, green roofs, PV's, glazing with thermal breaks, new recycled materials or new innovative systems. The building market is already being affected. New products promoting energy efficiency in buildings have been launched: new insulation materials, new types of glazing, cool materials and other building products, which contribute to a better energy performance of buildings.

According to the new regulation KENAK, there is no obligation to use renewable energy in buildings. There are, however, good examples of initiatives to promote the use of renewable energy, like Law 3851/2010 [8] on the electricity production from renewable energy sources and cogeneration and the recently proposed financial and practical incentives to stimulate as well the low scale and building installation of PV's by simplifying the installation procedures. According to those, the PV installation up to $10 \mathrm{kWp}$ can be realized with a small permission of works by the Hellenic Ministry of Environment, Physical Planning and Public Works. This is a motive for citizens to install PV on their roofs without being involved in very time-consuming and costly procedures.

On the other hand, new innovative systems have been introduced for a better life. New materials have been tested in Europe and USA in order to decrease the indoor temperature in houses and achieve smaller electricity bills. Greece has to take into account the new technologies and follow the future of bioclimatic design.

The power consumption in the form of heat or electricity, besides being a significant economic problem, because of the high cost of energy, results in large scale atmospheric pollution, mainly carbon dioxide (CO2) which is responsible for the greenhouse effect and contributes to the gradual rise in planet temperature that causes extreme weather conditions and disasters. The reduction of energy consumption in buildings can be achieved by simple methods and techniques, using an appropriate building design (bioclimatic architecture) and energy efficient systems or new technologies, such as passive solar systems. [9] Bioclimatic architecture refers to the design of buildings (interior - exterior - outdoor spaces or materials) based on local climate, aimed at providing thermal and visual comfort, making use of solar energy and other environmental sources. Basic elements of bioclimatic design are passive solar systems which are incorporated onto buildings and utilize environmental sources (for example, sun, air, wind, vegetation, water, soil, sky) for heating, cooling and lighting the buildings. [10]

Energy self-sufficient buildings are rarely built because the generated energy does not always cover the energy demand of the building. Another reason why buildings are rarely designed individually 
energy self-sufficient, is the fact that there are restrictive opportunities for energy saving. Energy could be stored in batteries that are in fact relatively efficient, but these required battery systems are very heavy and contain toxic metals.

Torcellini P. et al. [11] submitted a good Zero Energy Building (ZEB) definition. A ZEB should first encourage energy efficiency, and then use renewable energy sources available on site. Wind resources for ZEB's are limited because of structural, noise, and wind pattern considerations, and are not typically installed on buildings.

Fuel cells and micro-turbines do not generate energy; rather they typically transform purchased fossil fuels into heat and electricity. Passive solar heating and day-lighting are demand-side technologies and are considered efficiency measures. Energy efficiency is usually available for the life of the building; however, efficiency measures must have good persistence and should be "checked" to make sure they continue to save energy. It is almost always easier to save energy than to produce energy. The most used sources in Greece can be said that coming from PV's because of long period sun in Greece. But the question is "What other primary sources can we take of advantage in Greece?" The answer is Water and wind.

Hydrogen could be a good energy solution, but the technology still has to be developed for the architectural practice. A review of Hydrogen and its properties is given below.

The construction of energy efficient buildings using innovative building materials such as phase change materials (PCM), in addition to improving indoor comfort, energy savings and costs, can be achieved by increasing their market value. Because of its ability to absorb and release energy at predictable temperatures, phase change materials are effective in controlling and maintaining the thermal environment in the building. The use of phase changing materials, materials stored latent energy storage is an effective form of heat. These materials can also contribute into a better living and can lower the energy consumption of a building. [12]

A combination system of sun power, water, wind power and PCMs, would be a very "green" system for a house, in order to decrease its energy consumption.

\subsection{Introduction of Hydrogen Energy}

Hydrogen has been used in industrial applications for more than 100 years. Hydrogen offers large potential benefits in terms of reduced emissions of pollutants and greenhouse gases and diversified primary energy supply. Like electricity, hydrogen is a quality energy carrier, which can be used with high efficiency and zero emissions and can be made from a variety of feed stocks, including natural gas, coal, biomass, wastes, solar sources, wind, or nuclear sources. Hydrogen vehicles, heating, and power systems have been technically demonstrated. Basic hydrogen technologies such as fuel cells are making rapid progress toward commercialization. If hydrogen were made from renewable or decarbonized fossil sources, it would be possible to have a large-scale energy system with essentially no emissions of pollutants or greenhouse gases. Despite these potential benefits, the development of a hydrogen energy system is often seen as a big technical and economic barrier especially for use in construction sector or private houses. The effect of hydrogen on a range of materials has been studied and there is extensive literature available on the properties of hydrogen and its effects on materials. With the appearance of hydrogen fuel cell applications, the following areas such as the storage of high pressure hydrogen in composite materials, the potential exposure of the public to high-pressure hydrogen fueling operations or the location of high-pressure storage containers, are new.

\subsection{Hydrogen properties}

Hydrogen is a flammable gas with a wide flammability range (4\%-75\% by volume) and relatively low ignition energy ( 0.02 millijoules). It has a very low density and therefore must be stored at high pressures (10.000-15.000 psi range) to achieve enough mass for practical use. The ease of ignition and high storage pressure of hydrogen create a large risk associated with hydrogen usage. Hydrogen is a light element. It is colorless and odorless so it is undetectable by human senses, it is a flammable gas and shows several key properties including a specific gravity of 0.0696 , which explains its powerful buoyancy, has a boiling point of $-423^{\circ} \mathrm{F}$, which means that it takes a lot of energy to liquefy hydrogen and that liquid hydrogen presents hazards as a cryogenic fluid, it has a liquid density of $4.23 \mathrm{lb} / \mathrm{ft} 3$, which means that it is a light liquid - there is more mass of hydrogen in a gallon of water than in a gallon of liquid hydrogen and finally due to the very low boiling point, a liquid release of hydrogen will rapidly vaporize and very likely not reach the ground in liquid form. [13,14]. 
Hydrogen also has the ability to attack and damage to the point of leakage, certain materials that are used for the construction of storage containers, piping, valves, and other appurtenances. This destructive capability is sometimes referred to as hydrogen embrittlement. The mechanisms of hydrogen embrittlement can be complex and vary with several physical parameters including temperature and pressure. Hydrogen's ability to escape through materials based on its destructive abilities and small molecule size also contributes to the risk associated with hydrogen usage. [15].

Hydrogen is non-toxic. It is also non-poisonous and will cause no ill effect if inhaled with ambient air. Hydrogen is not a pollutant. A release of hydrogen is not known to contribute to atmospheric or water pollution.

Industry and building designers must consider the above properties when designing structures where hydrogen is used or stored and provides redundant safety systems including sensors and ventilation.

\subsection{Hydrogen production technologies}

Like electricity, hydrogen can be produced from diverse primary energy resources. Almost any energy resource can be converted into hydrogen, although some pathways are superior to others in terms of cost, environmental impacts, efficiency, and technological maturity. Development of clean, sustainable, and cost-competitive hydrogen production processes is essential to the market success of hydrogen-powered systems. The production technologies fall into three categories: thermal, electrolytic, and photolytic processes. [16].

The Electrolytic Processes that water electrolysis uses electricity to split water into hydrogen and oxygen is the most known process in industry. Electrolysis is considered as the cheapest way to produce hydrogen, when the required electricity is derived from renewable energy sources. Hydrogen produced via electrolysis can result in zero greenhouse gas emissions, depending on the source of the electricity used. This process gives one production technology that called water electrolysis. Water electrolysis technology is the most flexible solution to store renewable energy on a large, long-term scale. Using excess renewable electricity the electrolyzer splits water into its constituent parts, hydrogen and oxygen, that can be stored in common tanks. While each hydrogen production technology faces specific technical challenges, some common hurdles exist for most of the technology options. Industry are investing in research, development, and demonstration activities to address these challenges and pave the way for successful commercialization and widespread use of hydrogen as an energy carrier.

Purity is a major issue for any hydrogen system intended for use in fuel cells. Hydrogen production technologies must therefore either produce high-purity hydrogen outright or follow additional purification processes in order not to produce pollution. [17].

Today's capital costs for many hydrogen production technologies are substantially higher than those for other fuels. Developers are working to reduce these costs by applying the hydrogen principles, identifying better materials, decreasing the number of necessary parts, designing simplified systems, and moving into mass production.

Problems such as developing more durable, long-lasting and less expensive membranes, lowcost reactors and receivers, balance storage and production rate capacity for variable demand, increase reliability for high-temperature units and design manufacturing processes for high-volume production at low cost making the use of hydrogen systems difficult to expand their use.

\subsection{Hydrogen Transmission and distribution}

Most existing hydrogen fuelling stations dispense fuel from compressed gas metal tubes that are delivered to the station. This is the most economic system for locations with low fuel demand, if the delivery distance is not too great, and it might be the most suitable in the future in some locations. The principle advantage of tube trailer delivery is that it avoids the high liquefaction cost and high pipeline investment costs that affect other delivery systems. Tube trailer fuelling stations can be cheaper than other hydrogen fuelling stations because the hydrogen is dispensed directly from the tube trailer on-site storage as it is required. Fuelling stations tend to be small because a single tube trailer can store only 250-500 kg and it is impractical to replace the trailer lots of times per day. High costs are the principle disadvantages of tube trailer delivery, particularly for long-distance deliveries. Tube trailers are competitive at short delivery distances, but if the demand is very high then pipelines are a more economic option.

Pipelines are the most efficient method of transporting large quantities of hydrogen, particularly over short distances. Transporting hydrogen through high-pressure steel pipelines is more difficult than 
transporting methane because of hydrogen embrittlement, which makes strong steel pipes vulnerable to cracking, and because of hydrogen attack that allows reactions with the steel carbon atoms under certain operating conditions, again leading to cracks. [19] Pipelines are one of the most difficult delivery methods because the capital investment costs and energy efficiencies depend on the pipeline length, the diameter and the chosen throughput. Also the regulation or the infrastructure in some countries, like in Greece, is now yet introduced, for housing distribution.

\subsection{Hydrogen storage systems}

The need for a complete energy storage solution is becoming more important in our days. It's a well-known problem for the industry, and there are a number of energy management and storage systems today, but few offer a complete solution. Current buildings are energy dependent on their environment. When we run out of the fossil fuels, renewable energy technologies can and will become more visible in buildings. The hydrogen technology can be a good solution for energy storage because it can be produced out of water. The production can be done by electrolysis, which is driven by renewable energy sources, such as solar and wind energy. The water can come from nearby seas, "green" roofs, drainage, rain water or other possible sources. There is no $\mathrm{CO} 2$ emission during the production and use of hydrogen.

The storage is not heavy as a battery system, and it contains no toxic metals so the hydrogen technology can become feasible for buildings. At the moment, several kinds of technologies of hydrogen storage are available. Some of them will be briefly described here.

1. The simplest way is the compressed $\mathbf{H 2}$ gas. It is possible at ambient temperature. However, the density of storage is low compared to other methods.

2. The Liquid $\mathbf{H 2}$ storage is also possible: from $25 \%$ to $45 \%$ of the stored energy is required to liquefy the $\mathrm{H} 2$. At this method the density of hydrogen storage is very high, but hydrogen boils at about $-253^{\circ} \mathrm{C}$ and it is necessary to maintain this low temperature, and good insulation is needed.

3. In metal hydride storage the powdered metals absorb hydrogen under high pressures. During this process heat is produced upon insertion and with pressure release and applied heat, the process is reversed. The main problem of this method is the weight of the absorbing material - a tank's mass would be much heavier compared to that of a compressed $\mathrm{H} 2$ gas tank.

4. More popular at this time is carbon absorption: the newest field of hydrogen storage. At applied pressure, hydrogen will bond with porous carbon materials such as nano-tubes. [20, 21]

Hydrogen can be a good energy storing solution, but the technology still has to be developed for the architectural practice, so there are no fully hydrogen powered projects built on such a public building scale.

A good example of hydrogen technology in architecture is the Amsterdam Pavilion which is a business and science center in Amsterdam north at the NDSM old shipyard-terrain.

The researchers gave an answer to the question 'What are the possibilities for hydrogen as an energy carrier in combination with renewable energy in buildings and how both technologies can integrate as an architectonic aspect in the design?'

\subsection{The Amsterdam Pavilion example}

A small pavilion was designed based on the research of Bernard Aukema in 2012 [22] and hydrogen technology researches. The location for the project in Amsterdam was chosen because of the environmental conditions and the local area. At the chosen location there was a lot of wind, and there were no obstructions that could block the solar irradiance. There was also chosen a floating pavilion, which means that the building could easily turn into the sea. It could rotate with the sun, which increases the amount of energy that could be generated. The research was divided in to three aspects: Generation of energy, storage of energy and use of energy. These three aspects were researched separately and all three led to led to the use of solar panels and a wind turbine for energy generation.

In order to make the wind energy profitable, a very large flow area for a wind turbine and solar panels were required. The wind turbine was chosen because it was very stable, had not so much vibrations, had a good efficiency and also was consistent with the shape of the design.

There is a difference between horizontal and vertical-axis wind turbines. The horizontal orientated wind turbines are the most famous but today the three-blade wind turbines have established. The disadvantage of these wind turbines was that they run very fast, and this would cause vibrations. This is not really desirable in buildings, especially if they are constructed from reinforced concrete like most of the buildings in Greece. The idea was to construct a building from steel materials that absorbing small movements and vibrations. The vertical wind turbines have the advantage to be always directed 
correctly on the wind. Vertical-axis wind turbines use the lift principle and in theory could reach $59 \%$ efficiency. This is the maximum amount of energy we can generate out of a certain flow surface.

In addition to this, there was chosen photovoltaic solar cells, which are mainly focused towards the sun. Furthermore, the angle of the sun panels was adaptable to the angle of the sun. All the above calculations have been made due to Amsterdam environmental conditions and the place that the building had to be constructed. It was also taken into account the type of PV cells and the efficiency.

The energy that generated was converted into hydrogen through electrolysis of water. One advantage of electrolysis is that the energy is stored as a gas, and not in a heavy battery, which contains harmful toxic metals, which gets a lower quality over time. A disadvantage of hydrogen storage is that it requires a large volume. To solve this problem, the gas was compressed, which has the effect that at higher pressures, a stronger tank is needed and the compression to higher pressures costs more energy. So it was desirable to keep the pressure as low as possible. In the design the compression tanks were stored in the foundations of the building. The tanks were protected from the outside with air tanks that stabilized the building. This is because the construction was floating.

If you want to produce hydrogen gas out of water from the architectonic environment, we can state that this water will never be pure $\mathrm{H} 2 \mathrm{O}$. The best water could be rain water, but also that water should be purified or at least filtered. The same problems will occur with seawater. Because of the pollution, the electrolyzers can become clogged. An option is to filter the water, using a semi-permeable membrane, but that cost energy in the form of pressure.

The use of wind and solar energy is not always trustworthy. If it is not windy, less energy is generated, the same for sun-energy when the sun is not shining. Both systems have advantages and disadvantages. A major advantage of wind energy is that wind energy can also be produced at night. Solar energy can only be produced during the day. Furthermore, solar energy is very sensitive to the direction and angle of the sun. If the panels are not orientated right, less energy will be generated.

In the design the solar panels could complement with the wind turbine. Besides wind energy, solar energy was integrated in the design as photovoltaic solar cells (PV-cells). Photovoltaic solar cells can produce electric voltages upon exposure to light. The building in Amsterdam was consisted of a wind turbine that generates wind energy, solar panels (PV-cells) and storage tanks, located in the 'legs' of the building. Hydrogen was generated with the energy from the solar panels and wind turbine and would be compressed and stored in the middle of the legs. The outer tanks were used for the floating stability of the pavilion. The system had also a floater, at the water level. The building was separated from this floater. [22]

Finally, after assumptions and calculations, the proposal was to make hydrogen and oxygen out of solar energy and rainwater, to use hydrogen and oxygen to produce electricity. Wind energy will be used to compress the gases to their tanks and to purify the water before the electrolyzers split the water. The electrolyzer's membrane and catalysts work to take advantage of an electrochemical reaction in order to separate the oxygen and hydrogen molecules of water. The explosive hydrogen tanks were placed outside the building and the oxygen tanks were placed in the entrance hall. The fuel cells would be operational in the winter periods, so this heat was used to heat the building. Also the air that is blown through the fuel cells warmed up and could be used as warm ventilation air.

Even if Dutch engineers managed to design an autonomous "green" building like this, the cost is very high. In Greece there is a problem in building regulations and it is very difficult for engineers to take permits for a construction like this, because of earthquakes. There is also a problem in building regulations for using new systems for heating and cooling. If we follow the European Union's regulations for 2020 , Greece has to achieve a $20 \%$ lower use of carbon dioxide and to add $20 \%$ new "green" materials and $20 \%$ more renewable energy in construction, new systems have to be imported. Although hydrogen is not always more efficient than a battery system, it has a lot of advantages, as described in the report. In combination with renewable energy it seems to be feasible in architecture.

The central question in this detailed installation system is 'Is enough electricity? If there is not enough electricity that generated by the solar panels during winter or night, hydrogen will be transformed into electricity. If there is too much electricity during summer or day, water will be split and hydrogen and oxygen will be stored in tanks. The situation is feasible when the tanks do not run out of hydrogen in the winter period.

The hydrogen expression is an important aspect. The next thing in construction is the materialization of electrolyzers or the use of materials that will decrease the energy consumption that we can produce from renewable sources. A new approach in construction is the import of Phase Change Materials.

\subsection{Phase change Materials in buildings}


Phase change materials (PCM) represent an innovative solution that can contribute to the improvement of the energy performance of buildings. Phase change is the transition of a system from one state of matter to another by heat transfer. For example, from a solid state a material can change to a liquid state or from a liquid state a material can change to a gas. Heat transfer is the process of thermal exchange between different systems. Generally the net heat transfer between two systems will be from the hotter system to the cooler system. Heat transfer is particularly important in buildings for determining the design of the building and for designing the passive and active systems necessary to deliver the required thermal conditions for the minimum consumption of resources.

Home heating accounts for $35 \%$ of the average domestic power bills. The reasons that engineers want to reduce this usage are both financial and environmental. Financial reasons are clear, the less money spent as an individual or business on energy needs, the more money available for other things. Ecologically, awareness in the general population of the growing need to reduce human use of finite natural resources is increasing. Further to this, comfort and health resulting from appropriate conditions in the interior environment are a factor. Providing warmer, more efficient homes in the future is good for not just the individuals but has become essential for every nation.

PCMs, although much more expensive than available lightweight insulation materials in their current state of development, also have the potential to reduce the energy needed for space heating and cooling whilst improving the comfort of the space, in residential applications. This is because better use can be made of the "free" energy of the sun coming through windows.

\subsection{Phase change materials (PCMs) applications}

The applications of phase change materials increasing rapidly. PCM applications in green buildings include several development models. Anyone with thick brick or stone walls has probably noticed that their home takes a long time to heat or cool during the day. This is because for years engineers have employed high mass materials that slow the flow of temperature, as a means to build passive, eco-friendly buildings. While these materials work well at regulating temperature fluctuations, they can be expensive, require additional structure and eat up building square footage. Thankfully, scientists have been working hard on developing the same technology, but on a microscopic level, in the form of phase change materials. [23, 24]

The basic idea of passive buildings and thermal mass, is building materials with a high mass (water, stone or concrete) collect and store heat throughout the day, and then slowly release it as the temperature drops. Ideally this design technique is used in climates that have extreme temperature fluctuations from day to night, or season to season like in Greece. The thermal mass in a building's efficiency reduce the need for heating and cooling equipment — and is done so without any moving parts.

Phase change materials (PCM) provide thermal mass, but on a much smaller scale. PCM work by melting and solidifying at a specific temperature - heat is absorbed at the solid state, and when the material reaches a standard temperature, it changes to a liquid and releases the stored energy (heat). When the temperature falls below a predetermined degree, the PCM re-solidifies and the process repeats. Most PCM must be encapsulated to be stored and prevent evaporation and absorption. [23, 24]

There are several sectors in building industry that are looking to incorporate PCM into their materials and products - some examples of this included in drywalls, windows, concrete and insulation in building applications. For example, when PCM are embedded into a drywall, an entire building is capable of storing energy, rather than just its exterior walls (where masonry is typically used). By using drywall embedded with PCM as thermal mass, instead of masonry, bricks or concrete, the building gains square footage that typically would've been lost to thick walls, and needs less structural support, which can get very expensive. Though a wide portfolio of PCM materials are available in nature, but there is hardly any single PCM which has all the desirable characteristics of an ideal PCM. So choice of PCM should be made according to the system necessity, the required operating temperature and the specific applications. The range is arranged into categories like organics, inorganics and eutectics. The most common PCM's come in the form of paraffin, non-paraffins, salt hydrates or metallics, each with their own advantages and disadvantages.

Phase changes can be a mechanism for heat transfer in buildings. When systems change phase, they absorb or release significant amounts of heat energy. The systems themselves do not change temperature as the energy generated by the physical process of changing the state of the system.

For example, when water evaporates, it absorbs heat, producing a cooling effect. So when water evaporates from the surface of a building, this has a cooling effect. Conversely, when water condenses it releases heat. 
Phase change is also important in refrigeration, where refrigerant gases absorb heat from the cooling medium as they evaporate, and release heat when they condense, which is rejected to the outside (or recovered). The exact opposite of this process is used to generate heat in heat pumps.

Phase change materials are used in a range of applications in the technical and building sector. In the latter case, they are mainly used in walls and ceilings, drink cooling, drink vending, air conditioning, cooling, water heating, solar heating, waste heat storage, heat rejection systems, telecommunication shelter cooling, electronic / battery cooling or heat pumps. [25- 27]

However in the recent years a trend towards integrating these materials into transparent envelope components is being observed.

Considering the fact that the transparent envelope components, particularly in warm climates, are more vulnerable to thermal losses due to their higher thermal transmittance and higher radiation losses, the incorporation of phase change materials into transparent components is a special importance.

More than 500 natural and synthetic PCM are known. They differ from each other by their phase change temperature ranges and their heat storage capacities. Other properties of PCM for a high efficient cooling system with thermal energy system include the melting temperature in the desired operating range where in construction this would be $23^{\circ} \mathrm{C}$ or $26^{\circ} \mathrm{C}$, the storage of the amount of heat per unit of volume, minimizing the area of PCM tiles that are needed, high thermal conductivity where the quicker the PCM reacts to changes in temperature, the more effective the phase changes will be, congruent melting that means that the composition of the liquid is the same as that of the solid, which is important to prevent separation and super cooling, the reversible freezing/melting cycle, the durability over a large number of cycles and if the PCM is flammable or not.

Some of the most known PCM in global market are the following:

- Bio PCM: It is a rolled mat that contains PCM and it is installed between insulation and drywall layers and can be located in walls and ceiling.

- Glass X: It is an insulated glazing unit that can be used as full glass walls and windows. The unit has an outer pane of glass that reflects high-angle sun and allows low-angle sunlight to pass. Sunlight that is transmitted through this outer glass passes through inner polycarbonate channels that are embedded with salt-hydrate PCM. These PCM store the heat from the sunlight, and release the heat to the interior of the building as the temperature cools.

- Thermal CORE: It is a drywall panel embedded with paraffin PCM. The microscopic paraffin capsules absorb and distribute heat as the wax melts and solidifies with temperature fluctuations. [24, 28-31]

Construction applications use phase-change materials as they change between their solid and liquid states, rather than between a liquid and a gas state, as the volume change is far less. This does present the practical problem of containing the material in its liquid state. An effective solution here is microencapsulation. The idea is that the PCM, in the form of a wax, is contained in an extremely hard plastic shell. The capsules have a very large surface-volume ratio; they allow a high level of heat transfer, while also protecting the paraffin to keep it in its pure form. Pure paraffin is a suitable material for the wax because it undergoes less expansion than other PCM, maintains its form in a liquid state and is highly durable. The most known material is BASF Micronal DS microcapsules.

Because heat rises, an effective use of PCM microcapsules is to place them in a cassette and add them to a suspended ceiling tile. As paraffin is flammable, the PCM insert must be sandwiched between tiles in a material with a good fire reaction performance, such as metal. A metal tile also offers good thermal conductivity, pulling the heat through into the PCM. A typical loading of 50\% of the ceiling in PCM tiles will maintain the temperature in a typical mechanically ventilated area at $24^{\circ} \mathrm{C}$ for up to four to five hours. After that, the room will continue to heat up as before, until the heating load reduces. The other $50 \%$ of tiles can be service tiles or standard acoustic ceiling tiles.

With cooler night-time temperatures, the PCM will return to solid form, transferring the heat energy back into the room. This means that the room is not too cool first thing in the morning but at a comfortable working temperature, and the PCM tiles are reset for another day. Using metal PCM ceiling tiles in this way can lead to significant reductions in energy use. For example, 10 sq can store up to $2 \mathrm{kWh}$ of energy. Over a 30-year lifecycle, this saves 6MWh of thermal energy. The most known PCM ceiling material is the Armstrong Cool Zone product. This system is currently being trialed and preliminary results show that it is working well.

Dupont's Energain is another PCM that is used in construction. It consists of paraffin-based gel held between two sheets of conductive aluminum which is designed to be sealed behind plasterboard walls or above ceiling panels so that they act as a fire-retardant barrier to the material. The PCM is formulated to absorb heat above $22^{\circ} \mathrm{C}$, storing it until the temperature drops below $18^{\circ} \mathrm{C}$, when it releases 
it back to the room. It is claimed that it can help reduce heat consumption by $15 \%$ and air conditioning costs by $35 \%$. [28-31]

Infinite $\mathbf{R}$ is a triple layer membrane both flexible and tough. The product changes from a dense solid to a liquid. It can be used for ceilings, roofs and external or internal walls. Infinite $\mathrm{R}$ acts as a thermal energy sponge that intercepts and absorbs heat energy, then releases it later as the heat source is removed. Unlike traditional thermal mass applications however, Infinite $\mathrm{R}$ releases its heat only at one specific temperature. This enables Infinite R to slowly release its trapped thermal energy over a longer period of time thereby modulating room temperatures and reducing thermal loads. [32]

All the above materials although they are more expensive than the conventional product they replace, other expensive products have found a place in making the low energy/zero energy building, such as photovoltaic panels and high specification glazing systems. The momentum for the widespread use of PCM has started but the accessible information has been limited. Many PCM materials are undergoing testing as it is very difficult to be applicable for a variety of climates and desired temperature ranges. However, many PCM products are already being integrated into the construction industry in Europe. This seems like such an innovative, yet simple idea, and we're eager to see how it evolves within the Greek building industry.

In 2015, Murat Ozdenefe and Jonathan Dewsbury [33] studied through simulation the effect of incorporating a phase change material wallboard with a phase change temperature of $26 \mathrm{C}$ in a house in Cyprus. A lot of scenarios were considered for the same building geometry, each having different constructions. Two construction styles were used: perforated clay brick walls with reinforced concrete slabs and cellular concrete block walls with cellular concrete slabs. Each construction style was used in two different thicknesses. Simulations were carried out for the city of Larnaca for the cooling season only (May-October). The results showed that with this particular phase change material product, indoor air temperatures and cooling energies supplied to the building could be reduced by up to $1.7 \mathrm{C}$ and $14.0 \%$.

First, the buildings were simulated without any air conditioning system in order to find the resulting indoor air temperatures. Dynamic thermal simulations of a typical residential building from Cyprus were carried out with and without PCM linings. It has been found that the PCM lining is most effective in cellular concrete block walls with cellular concrete slabs, which is the one having thinner walls and slabs made up from lightweight cellular concrete. In each scenario, adding a PCM lining reduced in indoor air temperatures and cooling energies supplied. Therefore, it is concluded that this particular PCM product can be employed for excess temperature control and to reduce cooling energy supplied in houses in Cyprus. It is most effective in buildings that have a fast response to shortwave radiation and also a low capacity for heat storage. In particular, increasing the ventilation rate during the night when the air is relatively cool would increase the effectiveness of the PCM lining. [33- 35]

So as a result of the above, we could say that new technology applications for buildings will be very important in construction and in people's life. What we have to see next, is how to import this new system for Greek buildings and how we can connect sun, wind, water and PCM for an autonomous "Green building".

\subsection{A Greek model Future Case study}

In Greece it's an issue to allow wind and solar energy to be plugged into the grid without problems. A new law (L.4414/2016) was voted by the Greek Parliament in August 2016. [36] The purpose of this law is to develop a new scheme for renewable energy sources power plants, consistent with the Guidelines on State aid for environmental protection and energy 2014-2020. This new programme called "Net-metering". With the amendment of Law No.3468/2006 [37], a net metering system for autonomous producers is introduced for the first time in Greece. The new net metering scheme pertains only to solar PV systems and is applicable to all solar PV systems that aim for self-consumption, thus expands to both rooftop and ground-mounted systems. The upper limit for residential net-metering PV installations in Greece's mainland grid is set at $20 \mathrm{kWp}$. [38, 39]

This work will investigate an assumption for the use of a multi-complex system that contains PV solar panels, wind turbines, hydrogen fuel and PCM's, the thermal performance of a typical building in Greece and the effect of application of a particular passive technology with the aim of reducing indoor air temperatures and energy supplied for the cooling season. Phase change materials for passive building applications and hydrogen systems are a new technology and have not been tested for the buildings of Greece by computer simulation or practical application.

In order to examine the energy efficiency of single-family home in Greece, a two story building with basement and a flat roof was chosen as a representative single-family house type building. The average age of the building is close to thirty years. The house is designed for an average Greek family of four. It will occupy a total constructed area of $\mathbf{2 0 0 ~} \mathbf{~ m} \mathbf{2}$ with two floors. The description on the existing 
conditions of this representative building is based on information about the location, surrounding, environment, envelope shading, ventilation, domestic hot water, as well as details regarding the energy consumption behavior of the building.

Greece is characterized by hot climate conditions and long duration summer periods. Given the weather data obtained from the Greek Weather Authority (E.M.Y) [40], a possible location for the house to be built is on the Central Greece area in Lamia city (Lon) 220 26'09" / (Lat) 380 52' 35'/ h 17.4m. With an average temperature of $\mathbf{1 6 . 5}$ degrees Celsius, average wind speed of $\mathbf{3 , 6} \mathrm{m} / \mathrm{sec}$, average daily rainfall $\mathbf{4 7 , 8 1} \mathbf{m m}$ and an average of $\mathbf{2 . 5 1 7 , 1}$ sunlight hours per year and 4,28 $\mathrm{KWh} / \mathrm{m} 2$ daily solar radiation for a period of 15 years time. [41, 42]

Air conditioning units are the main cooling and heating devices installed in residential buildings in Greece due to the high costs of petrol. An average of $12.000 \mathrm{Wh}$ will be needed. A typical house in Greece needs the following appliances such as two TVs (700Wh), a washing machine (1500Wh), a dryer (1300Wh), a dish washer (1800Wh), a freezer $450 \mathrm{lt}(480 \mathrm{~W})$, a microwave (500Wh), a toaster (180Wh), a blender (127Wh), an iron and a vacuum cleaner (3500Wh), a desktop PC and a laptop (1300Wh), a DVD player and a stereo $(200 \mathrm{Wh})$, a hair dryer $(200 \mathrm{Wh})$, an electric stove $(7500 \mathrm{Wh})$, a coffee machine $(200 \mathrm{Wh})$, a boiler $120 \mathrm{lt}(3000 \mathrm{Wh})$ and finally the house lighting $(2500 \mathrm{Wh})$. The total daily power consumption is $\mathbf{3 6 . 9 8 7} \mathrm{Wh}$. This was calculated assuming all the home cooling or heating and electrical appliances are working at the same time.

A total yearly power of $\mathbf{1 3 . 5 0 0} \mathbf{k W h}$ has been calculated to be the amount of power needed by the family in order to live comfortable.

A "green house" in Greece can get its primary energy from geothermal heat, hydroelectric energy, wind energy or solar energy. Most of the primary sources are turned into electricity and then used conventionally for home appliances. The extra energy is used to convert water into hydrogen by electrolysis, for further storage, to fuel house during winter time or when we don't have enough wind or sun. When the system produces more electricity than the household requires, the excess is directed to the electrolyzer to produce hydrogen for further storage and usage. The use of PCM's in construction can help the final electricity costs of the house by reducing the temperature and use less electricity from cooling or heating equipment. A green house needs some extra water for the electrolysis procedure. This will come from the waste "grey water" of a green roof garden system, from the rain water or from the irrigation system of the garden. So a total autonomous off grid system for a Greek house can consist of PV panels, a small wind turbine and a hydrogen fuel system. This system has to achieve a total energy consumption of at least $13.500 \mathrm{kWh}$ a year.

A common PV system in Lamia city area in Central Greece has to be constructed with 30 degrees slope inclination and in south direction in order to achieve $100 \%$ efficiency. If PV sources cannot deliver the amount of energy needed by the house, the wind turbine and the hydrogen system will makes up the difference.

\subsection{PV Energy}

Designing a solar power system takes careful thought and planning. The size of the photovoltaic cells (PV) and its components are important. Photovoltaic cells are made of semiconducting materials. When sunlight is absorbed by these materials, the solar energy releases electrons from their atoms, allowing the electrons to flow through the material to produce electricity. The electricity generated by the PV cells will be used directly by the house appliances, while the extra energy generated will be used to power up the hydrogen electrolyzer. The utility interfaced solar power system includes: Photovoltaic cells, a combiner where the output of the array feeds to this component. This is needed to protect the individual circuits from the array and creates a single point output for the cable that runs out to the controller and an inverter that changes the DC current from the PV cells into 240 volt AC current. The potential for a $10 \mathrm{kWp}$ photovoltaic (PV) power plant is going to be examined in order to achieve the best solution for Lamia city area.

The area required for mounting a PV array depends on the output power desired and the type of module used. For a $10 \mathrm{KWp}$ PV we need 140 sq.m.

In 2012, J.G. Fantidis, et al. [42] investigated the PV output electricity in Greece by using the HOMER software. Given the global solar irradiation and the clearness index at a certain site, HOMER calculated the net energy output of the PV system. A part of this energy is lost in the inverter. The available solar potential almost coincided with the corresponding electrical energy consumption. It was obvious that higher values of solar radiation were considered during summer months and minor in the winter months. The electricity obtained from the $20 \mathrm{KWp}$ solar system for Lamia city was $\mathbf{3 0 . 0 0 0}$ $\mathbf{k W h} / \mathbf{y e a r}$. Assuming that for a 10KWp solar system, the electricity consumption is much less than that 
of a $20 \mathrm{KW}$, the electricity for the house will be nearly $\mathbf{1 2 . 0 0 0}-\mathbf{1 2 5 0 0} \mathbf{~ k W h} / \mathbf{y e a r}$. So there will be a difference of $1.500 \mathrm{kWh} /$ year that we need from another energy source.

Matzarakis A. et al. [43] measured the mean sunshine duration values for Lamia city (in hours) as given below.

\begin{tabular}{|c|c|c|c|c|c|c|c|c|c|c|c|c|c|}
\hline $\begin{array}{c}\text { Lamia } \\
\text { city }\end{array}$ & J & F & M & A & M & J & J & A & S & O & N & D & Year \\
\hline Hours & 102.6 & 90.4 & 163.5 & $\mathbf{2 0 9 . 9}$ & $\mathbf{2 8 0 . 2}$ & $\mathbf{3 1 6 . 7}$ & $\mathbf{3 3 3 . 8}$ & $\mathbf{3 2 0 . 0}$ & $\mathbf{2 4 8 . 1}$ & 177.1 & 148.0 & 126.8 & $\mathbf{2 5 1 7 . 1}$ \\
\hline
\end{tabular}

Table 1: Annual sunshine duration (in hours) in Lamia, Greece

From the above table, it is easy to understand that PV produces more energy between April to September. The problem is for the winter where the PV system doesn't achieve the maximum production. The renewable source we need to produce extra energy for the house will be the wind energy. We are going to produce energy from a system that contains small wind turbines, a tower and the inverter.

\subsection{Wind Energy}

Wind energy systems provide a cushion against electricity price increases and this is another way to produce hydrogen in a clean and sustainable way. Although wind energy systems involve a significant initial investment, they can be competitive with conventional energy sources when taken into account that future electricity costs are greatly reduced or avoided altogether.

The length of the payback period (this applies as well the Solar PV system) depends on the system to be chosen, the wind resource in the planned building site and how the wind system is going to be used. The selection of the site of a small wind turbine to be erected should be chosen carefully due to the complexity of the terrain.

The power in the wind is proportional to its speed. This means that the amount of power produced by the generator goes up exponentially as the wind speed increases. The wind system consists of a wind turbine, a tower, wiring, and the "balance of system" components such as controllers, and inverters. No batteries will be used since the extra electricity will be directed to the electrolyzer in order to produce hydrogen. Wind turbines will consist of a rotor and a generator mounted on a frame. Through the spinning blades, the rotor captures the kinetic energy of the wind and converts it into motion to drive the generator. Rotors can have two or three blades. The best indication of how much energy a turbine will produce is the diameter of the rotor, which determines the quantity of wind intercepted by the turbine. The frame is the strong central axis bar onto which the rotor and generator are attached. Because wind speeds increase with height in flat terrain, the turbine is mounted on a tower. Generally speaking, the higher the tower, the more power the wind system can produce. The problem is that we cannot use a tower in urban areas like Lamia city because of the local permits and the sound in urban areas. Finally an inverter will be used in order to perform exactly the same as with the PV cells.

In 2013, Bandekas D. et al. [41] calculated the net energy output of the wind turbine in Lamia city by using the HOMER software. The researcher found that in Lamia city the annual production of energy from a $2.5 \mathrm{KW}$ wind turbine was $3.190 \mathrm{KW} / \mathrm{year}$.

If we assume, that we use a small $1,5 \mathrm{KW}$ wind roof turbine in the house, the energy we can gain will be about $1.500 \mathbf{~ k W h}$ per year. So the contribution in electricity for a Lamia's city house will be $128 \mathrm{KWh}$ per month or $\mathbf{4 , 1} \mathbf{~ K W}$ daily. This is quite low efficiency for our demands but if we add 32,9 KW daily from the PV we have a total energy production of $37 \mathrm{KW}$ electricity from renewable sources.

As we can see form the above calculations, the electricity we produced for the house will be close to $13.500 \mathrm{kWh}$ per year. So there is not any other need for more energy. The problem is if we cannot reach the above KWh cause of small windy periods or from periods with no sun. Then we need some more energy that we have to produce it from water. All the energy consumption we calculated is coming to an average house in Greece per year.

The majority of buildings in Greece were built from the conventional building materials: brick and mortar, concrete (with or without steel reinforcement), steel or timber frames for structural components, insulation for reduction of the air conditioning load and brick walls within the buildings. Even if Greek engineers started to use better insulation materials and techniques we need to improve the indoor living of a house. The micro-encapsulated phase change materials with the filling on the basis of paraffin, built into mortars, walls, gypsum boards, glazing systems, ceilings or floors, provide passive conditioning of internal areas and reduction of energy consumption in buildings. 
Thermal characteristics of the existing buildings can also be improved by increasing their heat storing mass, by installing the PCM products which results in decrease of use of energy obtained from the combustion of fossil fuels emission of $\mathrm{CO} 2$ into the atmosphere.

Evaluations of the energy saving potential of PCM in building materials are limited but a lot of laboratory tests showed a reduction of cooling load between 10-15\%. In general, the available data suggest the initial assessment that PCM in building materials can reduce the annual consumption of cooling energy in residential buildings for as much $10 \%$, but that they do not significantly reduce the heating energy consumption.

Athienitis, Oliver et al. [44-46] concluded that gypsum wallboards attached on the vertical walls of an experimental outdoor test room in Montreal, reduced the total heating load of approximately $15 \%$.

But how much energy can we produce daily for electricity and heating/cooling appliances? As we said, the calculations for a $200 \mathrm{~m} 2$ dwelling appliances assumed to work at the same time. From ELSTAT the average electricity in a house is 59,8 \% for heating, 6,3\% for hot water, 17,4\% for cooking, $1,7 \%$ for cooling, $1,9 \%$ for lighting and $12,9 \%$ for the electrical appliances.

So an average house in Lamia city in Greece needs about $61,5 \%$ of its energy consumption for heating and cooling. If we take into account that our calculations were $12.000 \mathrm{Wh}$ from air-conditions, then by using PCM in construction we can reduce the heating and cooling loads by $15 \%$ is almost 1800 Wh reduction and finally the total daily power consumption is going to be $35 \mathrm{KW}$.

This source, for our investigation will be the hydrogen system. We are going to produce energy from a system that uses the extra electricity from PVs and wind turbine, in daily basis and the use of grey water from a green garden roof system or from rainfall water. A good stand alone hydrogen system would be at least $5.0 \mathrm{KW}$.

\subsection{The Hydrogen System}

This would be the most renewable option and is typical for fully and partially off-grid applications. In this case we can take power when it's available and use it to generate hydrogen by electrolyzing water.

This Hydrogen is then stored for periods when we do not have power available. A common scenario might be if we have solar we may use excess solar power during the day to generate hydrogen, then when the sun goes down or on a cloudy day we can consume the hydrogen we generated previously to generate electricity in the fuel cell. A typical hydrogen system contains an electrolysis generator, water tank, a storage tank, fuel cell and their components.

Hydrogen can be stored in many ways. Metal Hydrides is the most likely system to be chosen for the Greek house because the volume of the tanks is not large and has to do with safety issues. Metal hydrides are metallic alloys that absorb hydrogen into their molecular structure at contact. When the hydrides absorb hydrogen, they generate heat. The heat has to be removed from the hydrides in order for them to continue absorbing hydrogen until they reach a saturated state. Tanks need to be quite large and will be heavy which is not a problem because they will be placed underground near the house.

Metal hydrides are very attractive for hydrogen storage in consideration of their inherent safety and good performance characteristics. This system is able to store hydrogen inside of the metallic structure of the hydride: it's a more compact and safe solution in comparison with the traditional high pressure bottles. An alternative design is to store the hydrogen in a near-ambient temperature and atmospheric metal hydride (MH) storage. One advantage of the Metal Hydrides storage is that requires less space than a 120 bar pressure vessel with the same capacity. However, the greatest advantage is that it can be coupled directly to low pressure electrolyzers, thus eliminating the need for a compressor.

This system is able to store hydrogen inside of the metallic structure of the hydride. This is a more compact and safe solution in comparison with the traditional high pressure bottles. [47-51]

\subsubsection{The electrolyzers}

Electrolyzers generate Hydrogen by splitting the water molecule $\mathrm{H} 2 \mathrm{O}$ into its constituent elements Hydrogen and Oxygen in a process which is the reverse of the electrochemical action which takes place in a fuel cell. Electrolysis cells are characterized by their electrolyte type. There are two types of low temperature electrolysis: Alkaline and Proton Exchange Membrane (PEM). Both Alkaline and PEM technologies have the ability to deliver:

- On site and on demand hydrogen (load following)

- Pressurized hydrogen without a compressor

- $\quad 99.999 \%$ pure, dry and carbon-free hydrogen 
In alkaline electrolysis the reaction occurs in a solution composed of water and liquid electrolyte between two electrodes. When a sufficient voltage is applied between the two electrodes, at the cathode water molecules take electrons to make $\mathrm{OH}^{-}$ions and $\mathrm{H} 2$ molecule. $\mathrm{OH}^{-}$ions travel through the $30 \%$ $\mathrm{KOH}$ electrolyte towards the anode where they combine and give up their extra electrons to make water, electrons, and $\mathrm{O} 2$.

A PEM electrolyser uses an ionically conductive solid polymer. When potential difference (voltage) is applied between the two electrodes, negatively charged Oxygen in the water molecules give up their electron at the anode to make protons, electrons, and $\mathrm{O} 2$ at the anode. The $\mathrm{H}+$ ions travel through the proton conducting polymer towards the cathode where they take an electron and become neutral $\mathrm{H}$ atoms which combine to make $\mathrm{H} 2$ at the cathode. The electrolyte and two electrodes are sandwiched between two bipolar plates. The role of bipolar plate is to transport water to the plates, transport product gases away from the cell, conduct electricity, and circulate a coolant fluid to cool down the process. Some cooling will be required to cool down the process and produced gas, a water treatment system will be installed in order to produce demineralized water from the supplied tap water, rain water, a purification system will clean the hydrogen to deliver high purity gas according to the customer's specifications, a power rack will be installed to manage the power needed for the reaction (converting the AC current delivered by the grid into a direct current used for the process) and a control panel will allow the operator to have an overview of the complete package. All these wisely selected and specifically manufactured equipment will then either be installed in a building or packaged in an outdoor housing. $[52,53]$

Considering a most effective strategy regarding the supply of hydrogen to the consumer, water electrolysis from non fossil fuel power generation is appointed as the preferred method of hydrogen production. The electrolyzers that are based on Polymer - Electrolyte Membrane (PEM) separators and alkaline, can be used for this study, because they can achieve high efficiencies. The electrolyzers assume to be at least $6 \mathrm{KW}$.

\subsubsection{The fuel cell}

A fuel cell is a device that converts chemical potential energy (energy stored in molecular bonds) into electrical energy. A PEM (Proton Exchange Membrane) cell uses hydrogen gas (H2) and oxygen gas $(\mathrm{O} 2)$ as fuel. The products of the reaction in the cell are water, electricity, and heat.

There are many types of fuel cells, but they all consist of an anode, a cathode, and an electrolyte that allows positively charged hydrogen ions (protons) to move between the two sides of the fuel cell. The anode and cathode contain catalysts that cause the fuel to undergo oxidation reactions that generate positively charged hydrogen ions and electrons. The hydrogen ions are drawn through the electrolyte after the reaction. At the same time, electrons are drawn from the anode to the cathode through an external circuit, producing direct current electricity. At the cathode, hydrogen ions, electrons, and oxygen react to form water. Combined heat and power (CHP) fuel cell systems are used to generate both electricity and heat for homes. The system generates constant electric power and at the same time produces hot air and water from the waste heat. As the result these systems have the potential to save primary energy as they can make use of waste heat which is generally rejected by thermal energy conversion systems. From the energy we decrease from using phase change materials we can have a lower electricity of $15 \%$ so the extra electricity can be used for the production of Hydrogen.

The fuel cell will be placed in the back of the garage with the hydrogen fuel pump. The fuel cell stack combines the hydrogen with oxygen and produces electricity. In order to get the energy from the electrons in the hydrogen atom, the proton exchange membrane (PEM) in the fuel cell splits the hydrogen into protons and electrons. The electrons provide energy and are combined again with the protons on the other side of the PEM. There they combine with oxygen and leave the fuel cell as a water molecule. [53]

The power generation will be achieved by the use of a stationary fuel cell stack located in the house garage rated to $5 \mathbf{k W}$ of output power.

\subsubsection{Battery as electricity storage -converters - Hydrogen and water control system}

The battery is typically used in photovoltaic-hydrogen system. In our system battery has priority because it has less inefficiency comparing to the fuel cell. Neither electrolyser nor fuel cell can start without electricity, therefore battery should be considered in the system. The key physical properties of the battery are its nominal voltage, capacity, lifetime and minimum state of charge. Our system also needs a converter of $48 \mathrm{~V} \mathrm{DC}-220 \mathrm{VAC}$ and finally a hydrogen and water control system. What should first be borne in mind when choosing a suitable control system is that best energy use occurs when it is 
sent directly to meet load demands, next best is when it passes through the battery and lastly when hydrogen transformation takes place.

\subsection{Conclusion}

The purpose of this article is to define and design a stand - alone off grid power system based on renewable energy sources. These sources will be sun, wind and water. Due to environmental conditions, this system is going to be tested in a Greek house. The house is located in Lamia city in Central Greece. The construction of the house will follow the Greek Regulations, Laws and Energy Performance of Greek Buildings Directive. The energy consumption of a typical two storey dwelling of $200 \mathrm{~m} 2$ was calculated in addition to its construction materials and the environmental conditions of the area. An assumption of the use of Phase change materials in its building envelope has been made.

The house will consist of heating system, cooling system and the house appliances. The power system will consist of photovoltaic array, wind turbines and hydrogen technology based energy storage system. Energy storage system will consist basically of the electrolyser, the hydrogen storage tank and the fuel cell. Excess solar energy can be used by electrolyser for hydrogen production. Produced hydrogen will be stored in the tank for subsequent use in fuel cell for power production. The power system will be controlled by automatic control. If the stand alone system cannot provide the energy that the house needs, then "grey" water from a green roof or rainfall water can be collected to produce more hydrogen.

Phase change materials (PCM) represent an innovative solution that can contribute to the improvement of the energy performance of buildings. Recently a trend towards integrating PCMs into transparent envelope components is observed. This article aims to present the main solutions proposed in the literature for applications in the past few years for PCMs integrated into buildings elements. All of the PCM have good potentials to reduce heating and cooling loads by enhancing the storage capacity of the building envelope. Further research is recommended and more tests required for a "Green" Greek house in order to use different types of construction. The potential use of PCMs in construction material, heat transfer and other applications are promising. PCMs should be incorporated further in Greek energy management solutions due to the stress for innovations with a low impact on the environment. Energy storage can play an important role in the development and operation of environmentally friendly renewable energy systems. The integrated water, wind and solar energy system, based on long-term seasonal storage of electrolytic hydrogen, is considered as a promising solution to overcome the limitations associated with the intermittency of the renewable sources. Recent developments in fuel cells are beginning to make possible a promising alternative to batteries for storage of energy from solar or wind electric power systems. With this in mind, we designed an energy production-storage system based on PV, wind turbines and fuel cell concept. With such an integrated system, is expected to provide reliable, environmentally valuable power to house installations. Optimization of this system would be possible by successive computer simulations under various scenarios. In my opinion, it is the responsibility of the engineer to address the impact of existing residential buildings by retrofitting solutions with the aim of reducing the energy consumption and eventually improving the quality of life. Engineers, in collaboration with energy experts, can work properly to provide effective solutions. With the guidance of the new directive, along with their personal knowledge and experience in energy efficiency they can help bring about increased energy building performance.

This article is just an explanation depending upon simple calculations. To explore it further, a proper simulation tool or software is required, which will take into account the stand alone power system model equations with all the components mathematical models, so that the system performance can further be evaluated and analyzed. Also the cost of such systems, the health and safety regulations or the construction permits according to Greek Laws, are very important factors for the use of such a stand alone system or materialization techniques for Greek houses.

Bearing in mind that the electricity cost for consumers in Greece a lot of money, the present article demonstrates that hydrogen off grid autonomous power systems from renewable sources can play an important role in Greek energy generation.

\subsection{Declaration of conflicting interests}

The author(s) declare no potential conflicts of interest with respect to the research, authorship, and/or publication of this article.

\subsection{Funding}


The author(s) received no financial support for the research, authorship, and/or publication of this article

\subsection{References}

1. Centre for Renewable Energy Sources and Saving (CRES), Greece. National report for the EEI project "Monitoring of Energy Efficiency in EU 27, Norway and Croatia (ODYSSEE-MURE)". Energy Efficiency trends and policies in Greece". Available from: Odyssee and Mure internet database website http://www.odysseemure.eu/publications/national-reports/energy-efficiency-greece.pdf, September 2015.

2. Hellenic Statistical Authority (EL.STAT.) Wikipedia, free internet encyclopedia available from: https://en.wikipedia.org/wiki/Hellenic Statistical Authority.

3. Papadopoulou K., Papaglastra M., Santamouris M., (National Kapodistrian University of Athens, Greece) Information Paper P173 of ASIEPI European project. "Greece: Impact, compliance and control of legislation". September 2009. More information can be found at the ASIEPI project website: www.asiepi.eu or http://www.buildup.eu/sites/default/files/content/P173_Greece_Impact_compliance_control_ASIEPI_WP3.pdf

4. Hellenic Ministry of Economy and Hellenic Ministry for the Environment. Greek Regulation for the Energy Efficiency of Buildings (KENAK), Ministerial Decision A6/B/oık.5825/30-03-2010 FEK B'407.March 2010. Available from: http://www.ypeka.gr or http://www.buildup.eu/en/node/30206

5. Directive 2012/27/EU of the European Parliament and the Council - Energy efficiency, amending Directives 2009/125/EC and 2010/30/EU and repealing Directives 2004/8/EC and 2006/32/EC. Official Journal of the EU. November 2012.

6. Hellenic Republic Law 4342/2015 "Pension arrangements, transposition of Directive 2012/27/EE on energy efficiency amending Directives 2009/125/EC and 2010/30/EU and repealing Directives 2004/8/EC and 2006/32/EC". Official Government Gazette (FEK A' 143/09-11-2015), Greece, November 2015. Articles 3 - 12.

7. Hellenic Ministry of Environment \& Climate Change,"Energy Saving - Reduction of energy consumption in urban environment 'EXIKONOMO' project". Available from http://exoikonomisi.ypeka.gr/

8. Hellenic Republic Law 3851/2010 "Accelerating the development of Renewable Energy to address climate change and other provisions on jurisdiction of the Ministry of Environment, Energy and Climate Change". Official Government Gazette (FEK A' 85/04-06-2010), Greece, June 2010. URL of the publication: http://www.ypeka.gr 9. International Passive House Association (Ipha) "Passive house guidelines". Available from https://passivehouseinternational.org

10. Technical Chamber of Greece (T.E.E), Technical Guidelines of the Technical Chamber of Greece "BIOCLIMATIC DESIGN OF BUILDINGS, (TOTOE) 20702-5/2010, 1st Edition, January 2011. Available from: www.energynius.gr/files4users/files/TOTEE_20701_6_Final_TEE.pdf

11. Torcellini P., Pless S, Deru M., Crawley D, Renewable Energy Laboratory, U.S. Department of Energy, Zero Energy Buildings: A Critical Look at the Definition, National, Conference Paper NREL/CP-550-39833 June 2006. Available electronically at http://www.osti.gov/bridge

12. Zalba, B., Marin, J.M., Cabeza, L.F., Mehling, H. Review on thermal energy storage with phase change: materials, heat transfer analysis and applications. Applied Thermal Engineering 23, (2003) 251-283.

13. Rivkin C., Burgess R., and Buttner W. U.S. Department of Energy, Office of Energy Efficiency \& Renewable Energy, National Renewable Energy Laboratory. Technical Report NREL/TP-5400-60948, January 2015 Available electronically at www.nrel.gov/publications.

14. Wikipedia Free encyclopedia. Available at : https://en.wikipedia.org/wiki/Hydrogen

15. National Association of Corrosion Engineers (NACE), Texas, USA-Hydrogen Embrittlement, Available at https://www.nace.org/...101/Hydrogen-Embrittlement/

16. International Energy Agency (IEA), Riis T., Hagen E., Vie P. Ulleberg O, HYDROGEN PRODUCTION AND STORAGE - IEA PUBLICATIONS, January 2006

17. Zoulias E, Varkaraki E, Lymberopoulos N.,Christodoulou C. and Karagiorgis G.- Centre for Renewable Energy Sources (CRES), Frederick Research Center (FRC), Cyprus, "A review on water electrolysis". Available at www.cres.gr

18. Yang C., Ogden J. "Determining the lowest-cost hydrogen delivery mode", International Journal of Hydrogen Energy Vol. 32,2007, pgs 268-286

19. Dodds P., and McDowall W., UCL Energy Institute, University College London, UKSHEC Working Paper

No. 7 "A review of hydrogen delivery technologies for energy system models", 2012.

20. R. Krishna, E.Titus, M.Salimian, O. Okhay, S. Rajendran, A.Rajkumar, J. Sousa, A. Ferreira, J.Gil and J.Gracio "Hydrogen Storage for Energy Application", chapter 10, Titus et al., licensee InTech. 2012

21. M. Hirscher, Handbook of hydrogen storage new materials for future energy storage, Weinheim Wiley-VCHVerl. 2010

22. Aukema B, Architectural Engineering Lab 06, MSc Graduation Thesis - "Hydrogen in combination with renewable energy in architecture", 2012. Project website: http://www.h2architecture.com

23. Wikipedia Free encyclopedia. Available at $\mathrm{https} / / / \mathrm{en}$.wikipedia.org/wiki/Phase-change_material.

24. Apartment therapy Website Article, Green Architect on the Horizon: Building with Phase Change Materials by Thompson R.W Aug 18, 2010. Available at http://www.apartmenttherapy.com/on-the-horizon-building-with-p$\underline{124682}$

25. Mazlan A., Wahid A., Hasanen M. Hussen, and Mohammad A., Review Article "Review of Development Survey of Phase Change Material Models in Building Applications", Hindawi Scientific World Journal, Volume 2014, Article ID 391690, 11 pages, Published 11 September 2014 
26. Nader N., Bulshlaibi B., Jamil M., Suwaiyah M., Uzair M. Review Article "Application of Phase-Change Materials in Buildings", American Journal of Energy Engineering. Vol. 3, No. 3, 2015, pp. 46-52.

27. Yoon-Bok Seong and Jae-Han Lim, Article "Energy Saving Potentials of Phase Change Materials Applied to Lightweight Building Envelopes, Energies” Published 2013, Vol. 6, pgs 5219-5230.

28. Building 4 change Website Article No 474 "Quick facts: Phase change materials - The introduction of the CRC is set to drive the take up of phase change materials." Report from - Andy Pearson at 20/08/2010. Available at http://www.building4change.com/article.jsp?id=474\#.WG44zrkauv4

29. King J. Jr, DuPont Building Innovations, Hydrocarbon-based PCM Applications, Thermal Performance of the Exterior Envelopes of Whole Buildings XI International Conference: Thermal Mass VI Workshop, December 5, 2010

30. Armstrong World Industries Ltd. Building Products Division, Armstrong House, UK, Coolzone product brochure. Available at http://www.armstrong.com/commclgeu/eu1/uk/bw/coolzone.html

31. BASF SE, Business Management Micronal PCM, Marketing Polymer Dispersions for Construction, Germany. Micronal PCM brochure. Available at: www.micronal.de

32. Infinite R, Las Vegas, USA. Product page. Available at http://www.phasechangetechnologies.com/products

33. Ozdenefe M. and Dewsbury J. "Thermal performance of a typical residential Cyprus building with phase change materials", The Chartered Institution of Building Services Engineers 2015, Building Serv. Eng. Res. Technol. 2016, Vol. 37(1) 85-102

34. Florides GA, Kalogirou SA, Tassou SA, "Modeling of the modern houses of Cyprus and energy consumption analysis". Energy magazine, 2000 Vol 25, Issue 10, p. 915-937.

35. Lapithis P, Efstathiades C and Hadjimichael G. "Technical improvement of housing envelopes in Cyprus". In: Braganca L, Wetzel C, Buhagiar V, Verhoef LGW (eds) Improving the quality of existing urban building envelopes facades and roofs. Amsterdam: IOS Press, 2007, pp.9-20.

36. Hellenic Republic Law 4414/2016. Law on the new support scheme for renewable energy ("RES") and Cogeneration of High-Efficiency Heat and Power (“CHP”). Official Government Gazette (FEK A' 149/09-08-2016), Greece, August 2016.

37. Hellenic Republic Law 3468/2006. Generation of Electricity using Renewable Energy Sources and High Efficiency Cogeneration of Electricity and Heat and Miscellaneous Provisions. Official Government Gazette (FEK A' 129/27-06-2006), Greece, June 2006.

38. Hellenic Republic Ministry Decision No. АПЕН $/$ А/Ф1/oюк. 24461. Ministerial Decree "Installation of RES plants by autonomous producers under a net- metering scheme as it is foreseen by Law No. 3468/2006, art. 14a". Official Government Gazette (FEK B' 3583/31-12-2014), Greece, December 2014.

39. RES LEGAL Europe Official website. Legal sources on RES. Maroulis G. Article for Greece Net metering. Published 27-06-2016. Available at: http://www.res-legal.eu/search-by country/greece/summary/c/greece/s/res e/sum/140/lpid/139/

40. Hellenic National Metereological Service (E.M.Y). Climatology for Lamia city in Greece. Available at: http://www.hnms.gr/hnms/greek/climatology/climatology region diagrams html?dr city=Lamia

41. Fantidis J, Bandekas D, Vordos N. and Karachalios S. "Wind energy potential in Greece using a small wind turbine". 4th WSEAS International Conference on Theoretical and Applied Mechanics (TAM '13). January 2013. Available:https://www.researchgate.net/publication/257929879_Wind_Energy_Potential_in_Greece_Using_a_Sm all_Wind_Turbine D.V. Bandekas,2013

42. Fantidis J, Bandekas D., Potolias C., Vordos N. "Cost of PV electricity - Case study of Greece", Solar Energy journal. Vol. 91: p. 120-130, May 2013

43. Matzarakis A. and Katsoulis V. Sunshine duration hours over the Greek region, Article in Theoretical and Applied Climatology. Vol. 83, pg. 107-120, January 2006

44. Athienitis, K., Liu, C., Hawes, D., Banu, D. and Feldman, D., (1997), "Investigation of the thermal performance of a passive solar test-room with wall latent heat storage", Building and Environment journal, vol. 32 issue 5: pgs 405-410.

45. Lukić P., Tamburić J., Stojić D., "Energy Efficiency of buildings with PCM" Facta Universitatis Series Journal: Architecture and Civil Engineering, Vol. 10, Issue: 3, page: 343-352, 2012

46. Oliver A., "Thermal characterization of gypsum boards with PCM included: thermal energy storage in buildings through latent heat", Energy and Buildings Journal Vol. 48 (2012) pgs 1-7.

47. S.S. Makridis, Chapter 1: Hydrogen absorption for storage in Book: Methane and Hydrogen for Energy Storage, Invited chapter by Senior Editor for Power \& Energy with the Institution of Engineering \& Technology (IET), edited by R. Carriveau \& D.S-K. Ting, Turbulence \& Energy Laboratory, University of Windsor, Canada Book DOI: 10.1049/PBPO101E Chapter DOI: 10.1049/PBPO101E_ch1

48. E.I. Gkanas, S.S. Makridis, "Thermal Management of a $\mathrm{MgH} 2$ cylindrical tank including the thermal coupling with an operating SOFC during the dehydrogenation process", International Journal of Hydrogen Energy, Volume 41, Issue 13, 13 April 2016, Pages 5693-5708, 2016.

49. E.D. Koultoukis, S.S. Makridis $\dagger$, E. Pavlidou, P. de Rango, A.K. Stubos, "Investigation of ZrFe2-type materials for metal hydride hydrogen compressor systems by substituting $\mathrm{Fe}$ with $\mathrm{Cr}$ or V", International Journal of Hydrogen Energy, Volume 39, Issue 36, 12 December 2014, Pages 21380-21385, 2014.

50. E.D Koultoukis, E.I. Gkanas, S.S. Makridis $\dagger$, C.N Christodoulou, D. Fruchard, A.K Stubos, "High Temperature Activated AB2 Nanopowders for metal Hydride Hydrogen Compression", International Journal of Energy Research, 2014; 38(4):477-486. doi:10.1002/er.3147, 2014. 
51. S.S. Makridis $\uparrow$, E. Gkanas, G. Panagakos, E.S. Kikkinides, A.K. Stubos, P. Wagener, S. Barcikowski, "Polymer-Stable Magnesium Nanocomposites Prepared by Laser Ablation for Efficient Hydrogen Storage", International Journal of Hydrogen Energy, Volume 38, Issue 26, Pages 11530-11535, 2013.

52. Fritz D., Mergel J., Stolten D. A comprehensive review on PEM water electrolysis, International Journal of Hydrogen Energy, Vo. 38, Issue 12, 22 April 2013, Pages 4901-4934

53. Hydrogenics official website. Available at: http://www.hydrogenics.com/technology-resources/hydrogen technology/electrolysis/ 